\title{
Study on Control Theory of Landslide Based on the Evolution Process
}

\author{
Huiming Tang, Sha Lu, Xinli Hu, Yiping Wu, \\ Chengren Li, Chun Xiong, Ying Zhang \\ Faculty of Engineering, \\ China University of Geosciences, \\ 388 Lumo Rd., Hongshan District, 430074 \\ Wuhan, Hubei, China
}

\begin{abstract}
Current researches on landslide prevention are mostly based on time-displacement curve or some other corresponding characteristic parameters rather than landslide evolution. But landslide varies a lot from different mechanisms and evolution stages, it is necessary to study it from aspect of evolution. This paper presents a landslide control theory based on the evolution process. This theory includes landlside evolution mechanism, the evolution stage and process and the landslide control.

Baishuihe landslide in Zigui, Three Gorges Reservoir area is taken as a good example to illustrate the control theory. The geological information, location are served as the landslide evolution mechanism. Multi-field information monitoring is utilized in evolution stage part. Numerical method is used to predict the further evolution process so as to taken action in advance for controlling in landslide control part.
\end{abstract}

Keywords-control theory of landslide; evolution process; Baishuihe landslide; Three Gorges Reservoir area

\section{INTRODUCTION}

Landslides are frequent and world spread geological hazards that bring huge loss to human life and property. In China, the economic losses caused by geological disasters each year account for more than $25 \%$ of the total natural disasters ( $\mathrm{Li}$ et al., 2004). In many countries, the economic losses and casualties due to landslides are greater than commonly recognized, and landslides generate a yearly loss of property larger than that from any other natural disaster including earthquakes, floods and windstorms. (M.J. García-Rodríguez et al., 2008).

Landslides have been intensively studied by many scholars in the past several decades with advancement of new research methods and technologies. The distributed optical fiber sensing has been used for the evolution of landslide information (Shi et al., 2004). RS and GPS have been applied for the acquisition of landslide evolution information (Wang et al., 2003). In the aspect of prediction methods, early warning has been taken into the monitoring of landslide (Shi et al., 2005) and lessons learnt has been used for nonlinear prediction (Qin et al., 1993).

Landslide is a complicated phenomena involving many processes. The current landslide control is based on a single parameter of a certain period and evolution is not taken into consideration, which is obviously insufficient.
Meanwhile, the identification of landslide evolution process is the precondition and foundation of landslide prediction and warning. However, little research has been done into the study of landslide control based on the evolution process. Then it is profound to put up a control theory of landslide based on the evolution process.

To better advance the control theory for landslide, we choose a well documented landslide site Baishuihe as a research object. It is a landslide happens frequently in history. Geological analysis and surface monitoring data were used for controlling the deformation of Baishuihe landslide (Wang et al., 2009; Li et al., 2010). But no obvious progress can been seen in the control of it. Here, the control theory based on evolution process is used for the control of Baishuihe landslide.

\section{MethodOLOGY}

\section{A. Background and preliminary results}

The control theory of landslide based on the evolution process is a complicated system described as follows. The basic thought this theory is the evolution process, which is laid as the foundation of landslide control. To realize the control of landslide, first, landslide evolution mechanism, which includes the disaster-forming mode in disaster area and the multi-field evolution process and disaster-causing mechanism under major dynamic factor, should be studied. Then, under the basic of landslide evolution mechanism, it comes to the evolution stage and process. Three methods can be adopted in this study. They are a multi-field information monitoring and prevention system, the method of multi-field data analysis, and the method of landslide evolution identification. Finally, the landslide can be controlled by the control rules of landslide information and control theory and methods, which include landslide warning and landslide treatment.

Our research is focused on landslide evolution and process control. The landslide controlling mode concerned three key scientific questions. The first is landslide evolution and the mechanism. Second is the interaction mechanism of system structure of landslide and its prevention. Third is landslide evolution recognition and process control. A control system of landslide based on evolution has been set up and a landslide warning system based on the recognition of landslide evolution stage is created. New technologies are 
invented in the multi-field information investigation and monitoring of landslide evolution. Due to the landslide hazard prevention system based on evolution and the multi-field information investigation and monitoring, a large field of landslide hazard experiment demonstration base has been built. The base is mainly composed of test tunnel groups in Huangtupo, Badong and the interaction of landslide and its prevention structure tests groups in Majiagou, Badong.

\section{A CASE STUDY OF THE CONTROL THEORY OF LANDSLIDE BASED ON THE EVOLUTION PROCESS}

\section{A. Landslide evolution mechanism}

\section{1) Study area}

Baishuihe landslide is situated in Zigui County, on the southern bank of Yangtze River and $56 \mathrm{~km}$ west of the Three Gorges Dam. The elevation of crown is $410 \mathrm{~m}$ and the toe reach into Yangtze River. The main sliding direction is $18^{\circ}$. The dip of the landslide slope is about $30^{\circ}$, its length is $600 \mathrm{~m}$ and the width is $700 \mathrm{~m}$. The volume of the landslide material is about $1230 \times 104 \mathrm{~m}^{3}$ with an average thickness of about $30 \mathrm{~m}$ (Figure 1).
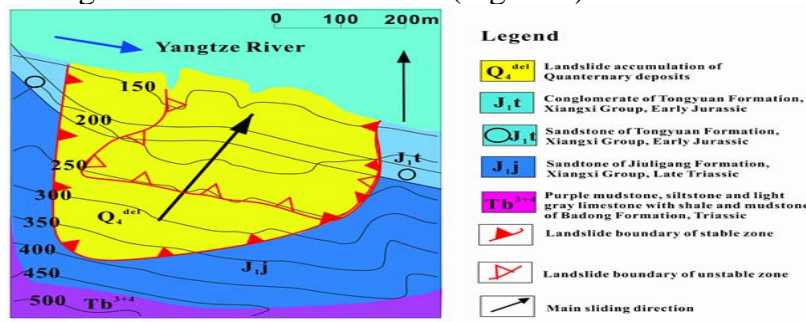

Figure 1. Geological plan of Baishuihe landslide.

\section{2) Geological structure}

Quaternary alluvial and deluvial gravelly soil and some block stone cover the upper layer of the landslide. Medium layered sandstone with thin beds of mudstone is existed in the landslide and their attitude is $15^{\circ} \angle 36^{\circ}$. On the aspect of tectonic, Baishuihe landslide is located on the west wing of Zigui syncline fold and it is characterized by monocline bedding slope. The effect of faulting is not obvious in the rock and joints are well developed.

3) Landslide formation lithology

Two slide surfaces are known to exist in the landslide. The upper slide surface is laid under the upper layer of quaternary deposits and middle layer of cracked rock. The thickness of the sliding zone is about $0.9 \mathrm{~m}$ to $3.13 \mathrm{~m}$ and mainly consist of silty clay. The lower one is between the middle layer of cracked rock and bottom layer of argillaceous siltstone. It mainly consists of silty mudstone containing carbonaceous material (Figure 2). The upper landslide bed is cracked rock, which is hard and compact structured. The lower landslide bed is argillaceous siltstone with carbonaceous material. It is relatively compact and hard. The landslide is divided into two zones, stable zone and unstable zone, according to the new slide surface.

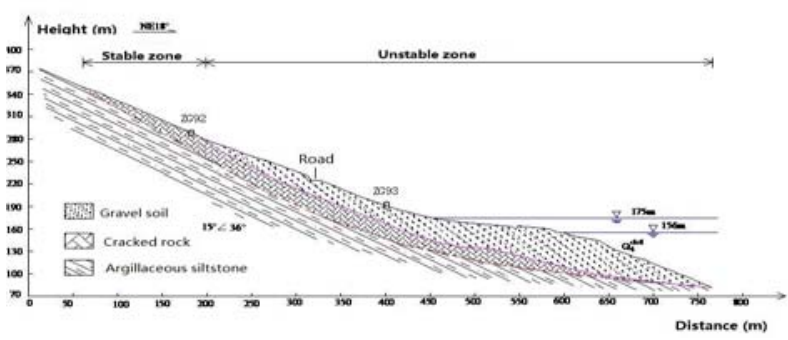

Figure 2. Geology profile of Baishuihe landslide.

\section{B. Evolution stage and process}

1) Multi-field information monitoring and prevention system

A multi-field information monitoring system is applied in the unstable zone to track the landslide evolution process. From 2003 to 2012, Baishuihe landslide is under continuous observation and monitoring.

Seven GPS deformation monitoring sites were established on the surface of the landslide. Two were set at the periphery of the landslide and four were added to the middle-low part of the unstable zone on May and October, 2005, respectively. These further improved the GPS monitoring network.

Two Fiber optics were set to monitor the landslide surface displacement. At the middle of the monitoring section of the landslide, one angle site is constructed beside each of the 3 GPS monitoring sites to ensure synchronization. At the mid-lower part of the middle monitoring section, two GPS were set to monitor underground water level. Since September 2004, they were changed to automatic successive measuring. Eleven NMR sites are set to the landslide. Continuous geological surveys are conducted in this monitoring to check the characteristics of surface and house deformation.

2) Data analysis

Visible deformation (Figure 3) is shown in the unstable zone of Baishuihe landslide. Discontinuous shear fractures are detected in the west boundary and a massive crack more than one hundred meters long and half meter wide is discovered near to the east boundary. The crown cracks at the southeast boundary tend to be more obvious.

From 2003 to 2012, the monitoring sites in the unstable zone, ZG93, ZG118, XD-01, XD-02, XD-03 and XD-04 showed synchronization deformation. Yearly, from May to September, there is obvious deformation due to the rainfall erosion and increase of water level (Figure 4). 


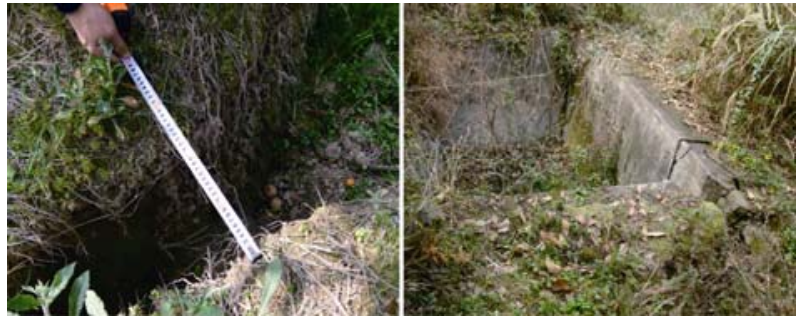

Figure 3. Geological deformation phenomenon.

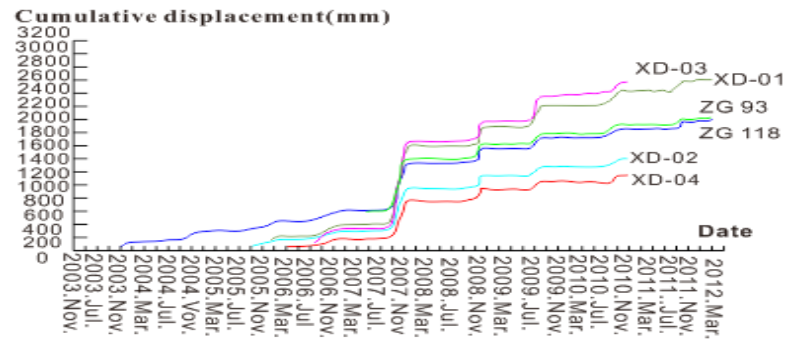

Figure 4. Cumulative displacement curve based on monitoring.

3) Method of landslide evolution identification

Three criteria are proposed for landslide identification as follows:

TABLE I. GEOLOGICAL CRITERION.

\begin{tabular}{|c|c|c|c|}
\hline Deformation phase & Slowly deformation stage & Severe deformation stage & Critical sliding stage \\
\hline & $\begin{array}{l}\text { Wiggly deformation happens } \\
\text { when the sheer stress of the } \\
\text { main slide surface exceeds the } \\
\text { shear strength. The cracks } \\
\text { become wider. One or more } \\
\text { ground fissures appear on the } \\
\text { surface or buildings, and } \\
\text { gradually connect to each other. } \\
\text { There is no obvious } \\
\text { deformation at sides and front } \\
\text { of landslide. }\end{array}$ & $\begin{array}{l}\text { Main slide surface is formed. Cracks at the } \\
\text { back boundary get more and wider. Land } \\
\text { subsidence appears. In some parts, the } \\
\text { ground is uplifted and some radial cracks } \\
\text { appear, followed by bulge fractures. } \\
\text { Dendritic-like cracks appear in the } \\
\text { upper-middle part and spread till the resisting } \\
\text { part. They finally connected with the shear } \\
\text { cracks. Landslide mass move forward and } \\
\text { the lower part is lifted and get soft because of } \\
\text { extrusion. Spring water increases or } \\
\text { decreases. }\end{array}$ & $\begin{array}{l}\text { Slip mass starts to slide down. As a whole the } \\
\text { gravity center decreases. The slide surface is } \\
\text { gradually cut from the ground, making the whole } \\
\text { slide surface interconnect and the landslide slip as a } \\
\text { whole part. The cracks get more and wider at the } \\
\text { back boundary. Slide cliff get taller and buildings } \\
\text { get tilted. The cracks at the sides and back of the } \\
\text { landslide connected with each other and two side } \\
\text { walls appear. Collapses at the front get more } \\
\text { obvious and animals become abnormal and springs } \\
\text { and wells become turbidite. }\end{array}$ \\
\hline
\end{tabular}

TABLE II. MONITORING CRITERION.

\begin{tabular}{|c|c|c|c|}
\hline Deformation phase & Constant rate stage & Acceleration stage & Severe sliding stage \\
\hline & $\begin{array}{l}\text { Displacement } \\
\text { increases gradually and the } \\
\text { landslide is at the constant } \\
\text { speed stage of creep. }\end{array}$ & $\begin{array}{l}\text { The displacement } \\
\text { increases more rapidly and it turns from } \\
\text { constant speed to acceleration. The } \\
\text { landslide is at transit of accelerated creep }\end{array}$ & $\begin{array}{l}\text { Displacement and the } \\
\text { velocity speed up and it is at the } \\
\text { critical sliding state. }\end{array}$ \\
\hline
\end{tabular}

stage.

TABLE III. NUMERICAL ANALYSIS CRITERION.

\begin{tabular}{llll}
\hline Deformation phase & Slowly deformation stage & Severe deformation stage & \multicolumn{1}{c}{ Critical sliding stage } \\
\hline $\begin{array}{l}\text { Process of sliding surface } \\
\text { formation }\end{array}$ & $\begin{array}{l}\text { Slide surface is formed with the } \\
\text { decreasing of rock and soil strength. }\end{array}$ & $\begin{array}{l}\text { Yield surface is formed and the it is } \\
\text { not going to slide. }\end{array}$ & $\begin{array}{l}\text { Strain at the slide surface } \\
\text { increases to failure stage. }\end{array}$ \\
$\begin{array}{l}\text { Stability coefficient change } \\
\text { Landslide time prediction }\end{array}$ & Long-term prediction & Short-term prediction & $1.01-1.04-1.01$ \\
\end{tabular}

\section{Landslide control through numerical simulation prediction}

According to the method of multi-field information monitoring and prevention system, various data can be obtained to know the real-time deformation and the evolution process of Baishuihe landslide. Thus, numerical simulation can be adopted to predict the future evolution trend of Baishuihe landslide. Two prediction models were set up to predict landslide evolution. They are prediction model based on potential energy consumption (MPEC) and displacement prediction of time series (MTS).

(1) MPEC prediction

This method simulate the energy consumption by 
FLAC $^{3 \mathrm{D}}$ of landslide in the evolution process. The potential energy changes slowly at first, then in constant speed and finally in acceleration stage. The energy changing process is in consistence with the evolution stages. When the percentage of potential energy costs reaches $20 \%$, the landslide is in the stage of acceleration formation.

Table.4 and simulation model (Fig. 5) show that the landslide reaches its maximum displacement when the water level of Yangtze River reaches the warning level of $175 \mathrm{~m}$, and the result is consistent with the monitoring result in reality. The maximum displacement for Baishuihe landslide is reached when the potential energy consumption per thickness is $\mathrm{W}=1.63 \times 10^{8} \mathrm{~N}$.m, and the consumption of the failure mode of the landslide is $1.87 \times 10^{9}$ N.m.

TABLE IV. PHYSICAL AND MECHANICAL PARAMETERS OF BAISHUIHE LANDSLIDE MATERIALS.

\begin{tabular}{llllll}
\hline $\begin{array}{l}\text { Rock and } \\
\text { soil mass }\end{array}$ & $\begin{array}{l}\text { Elasticity } \\
\text { modulus } \\
(\mathrm{GPa})\end{array}$ & $\begin{array}{l}\text { Poisson's } \\
\text { ratio } \\
\mu\end{array}$ & $\begin{array}{l}\text { Cohesive } \\
\text { force } \\
(\mathrm{KPa})\end{array}$ & $\begin{array}{l}\text { Internal } \\
\text { friction } \\
\text { angle } \\
\phi\left(^{\circ}\right)\end{array}$ & $\begin{array}{c}\text { Density } \\
(\mathrm{kg} / \mathrm{m} 3)\end{array}$ \\
\hline $\begin{array}{l}\text { Gravelly } \\
\text { soil }\end{array}$ & 1.0 & 0.20 & 120 & 20 & 2650 \\
$\begin{array}{l}\text { Slip band } \\
\text { soil of silty } \\
\text { clay }\end{array}$ & 0.1 & 0.20 & 29.8 & 14 & 2650 \\
$\begin{array}{l}\text { Cracked } \\
\text { rock } \\
\text { Argillaceous } \\
\text { siltstone }\end{array}$ & 3.6 & 0.24 & 200 & 40 & 2600 \\
\hline
\end{tabular}

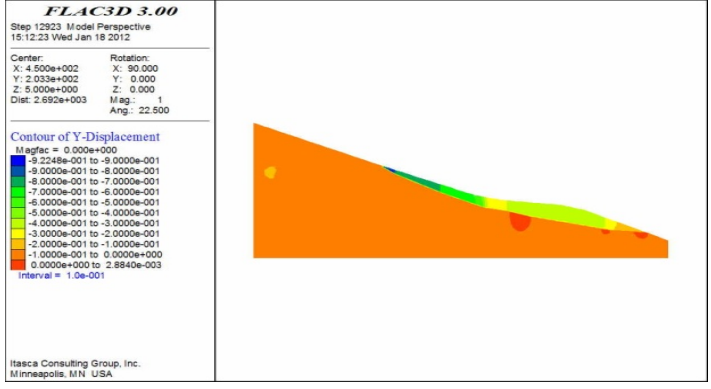

Figure 5. Prediction and measurement displacement curve.

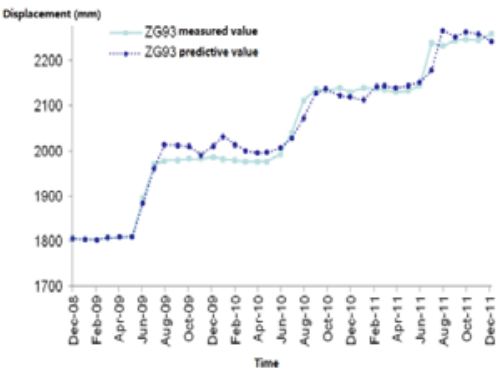

Figure 6. Vertical displacements of Baishuihe landslide in July 2007.

(2) MTS predictions

The accumulative displacement of Baishuihe landslide changes with time. The process can be seen as a time series. The model of unstable time series is applied to analyze Baishuihe landslide. The basic equation of the model is shown as follows:

$$
y(t)=D(t)+\varepsilon(t)
$$

$y(t)$ stands for the factor, which is time series; $D(t)$ stands for the functions of certainty. It usually consist of the trend functions of $f(t)$ and the period function of $p(t) ; \varepsilon(t)$ stands for the random functions.

The prediction and measurement displacement curve(Fig. 6) of ZG93 is taken as an example. The measured value curve shows the trend of increasing. The displacement values of the initial point of the two curves are about $1800 \mathrm{~mm}$. Both change slightly to reach the turning point in June, 2009 and then start to go up rapidly. The measured curve reaches another turning point of about $1990 \mathrm{~mm}$ and then increases gradually until June of the next year. It starts to increase rapidly in every June and starts to increase slowly in every October, and this is also the time that rains a lot. The maximum measured displacement value is about $2300 \mathrm{~mm}$. The predicted value shows the same tendency and finally reach the maximum point of about $2250 \mathrm{~mm}$. The measured curve and predicted curve are similar with each other in shapes.

\section{Discussion}

Under the foundation of evolution mechanism, a multi-field monitoring and prevention system is applied in Baishuihe landslide for its evolution stage and process identification. From partial monitoring data, relative conclusions on landslide stage and process can be drawn. According to Table 1, from partial geological deformation(Fig. 4) information we can conclude that the landslide is in the stage of severe deformation. According to Table 2, from partial monitoring data(Fig. 5), we can see the landslide is in constant rate stage overall but in November, 2007, it went through a period of acceleration 
stage. According to Table 3, different factor of safety can be obtained due to different displacent at different time so as to determine the process stage of landslide evolution.

At last, two numerical simulation prediction models are set up for Baishuihe landslide control by the evolution prediction. In the MPEC prediction, we calculate the potential energy consumption per thickness and the obtained result is $\mathrm{W}=1.63 \times 10^{8} \mathrm{~N}$.m. It is much smaller than the consumption at the failure mode, which indicates that the landslide is stable. The result is inconsistent with real condition. In MTS prediction model, we can see from Fig. 7 that the measured value curve is basically the same as the predictive one. It indicates the model can reflect the increasing of initial accumulation well and is consistent with reality. In this way, the landslide evolution process can be predicted according to data at hands. Relative measures can be taken in advance due to prediction so as to reach the effect of control.

\section{CONCLUSIONS}

In this paper, the control theory of landslide based on the evolution process is proposed and Baishuihe landslide is taken as a case to verify the theory. This theory includes landslide evolution mechanism, the evolution stage and process and the landslide control. In this research, a multi-field information monitoring and prevention system has been established based on many techniques like "3S", NMR, 3D laser scanners, optical sensors, acoustic emission instrument, GeoRobot, thermal infrared image etc.

On the core problem of landslide evolution process, Baishuihe landslide is controlled with the theory. Conclusions are drawn as follows:

(1) The control theory of landslide based on the evolution process is proposed and the case study of Baishuihe landslide properly suits the theory, indicating the theory is not only logical in words but also valuable in reality.

(2) The multi-field information monitoring system is a comprehensive real-time monitoring method that can provide in time data for further landslide control.

(3) Numerical simulation models based on potential energy consumption (MPEC) and displacement prediction of time series (MTS) is suitable for Baishuihe landslide prediction. The results of them both show consistence with real monitoring data. This in turn indicates predictions can be made from different fields so as to improve the accuracy of prediction.

(4) Though Baishuihe is a well documented landslide that can provide relative data for the study, still it can not wholly and comprehensively verify the theory. Some parts of the theory like the multi-field data analysis is not comprehensively obtained here. Therefore, more research has to be made for further verification of the control theory of landslide based on the evolution process.

\section{REFERENCES}

[1] Chen Xiaoqing, Cui Peng, Li Yong, Zhao Wanyu. Emergency response to the Tangjiashan landslide-dammed lake resulting from the 2008 Wenchuan earthquake, China. Landslides. 2011, 8: 91-98.

[2] Deying Li, Kunlong Yin, Chin Leo. Analysis of Baishuihe landslide influenced by the effects of reservoir water and rainfall. Environ Earth Sci. 2010, 60:677-687.

[3] García-Rodríguez MJ, Malpica JA, Benito B, Díaz M (2008) Susceptibility assessment of earthquake-triggered landslides in El Salvador using logistic regression. Geomorphology 95:172-191

[4] James C. Bathurst, C. Isabella Bovolo, Felipe Cisneros. Modelling the effect of forest cover on shallow landslides at the river basin scale. Ecological Engineering. 2010, 36: 317-327.

[5] Kuang-Tsung Chang, Ming-Lang Lin, Jia-jyun Dong, Chang-Hai Chien. The Huangtsaiping landslides: from ancient to recent. Landslides. 2012, 9: 205-214.

[6] Li Baoxiong. The method of forecast just before landsliding for loess landslide. The Chinese Journal of Geological Hazard and Control. 2003, 14(2): 27-30.

[7] Shi Bin, Ding Yong, Xu Hongzhong. The application of stress measurement of distributed optical fiber technology in early landslide warning. Journal of Engineering Geology. 2004, 12(Sl): 515-518.

[8] Shi Bin, Xu Xuejun, Zhang Dan. The feasiibility study of applying BOTDR strain monitoring techmology into the health diagnosis of engineering with large foundation. Journal of Rock Mechanics and Engineering. 2004, 23(3): 493-499.

[9] Tang Huiming. GIS system of landslide risk prediction for Badong County in the reservoir district of three Gorges project, China [A]. Proceedings of 2005 international Conference on landslide and Foundations, 18th Vancouver Geotechnical Society Symposium[C]. Greece, 2005, pp: 2078-2086

[10] Wang Shangqing, Xu Jinjun, Luo Mian. Study on warning of dangerous state of Baishuihe landslide in Three Gorges Reservoir Area. Geomatics and Information Science of Wuhan University. 2009, 34(10): 1218-1221. 